\title{
ANALISIS PENGARUH CITY BRANDING "GUNUNGKIDUL HANDAYANI" TERHADAP PENINGKATAN KUNJUNGAN WISATAWAN DI KABUPATEN GUNUNGKIDUL ( STUDI KASUS BAPPEDA DAN DINAS PARIWISATA)
}

\author{
Zuefa Choirunnisa ${ }^{1}$, Deny Tri Ardianto ${ }^{2}$, Rahmanu Widayat ${ }^{3}$ \\ 1,2,3Pacasarjana Seni Rupa Universitas Sebelas Maret \\ Universitas Sebelas Maret Surakarta, JI Ir. Sutami No 36A, Jebres, Kota Surakarta, Jawa Tengah 57126
}

Received: 10 Mei 2018

Revised: 18 Maret 2019

Accepted: 21 Maret 2019

\begin{abstract}
Abstrak: GUNUNGKIDUL HANDAYANI merupakan tagline dari city branding yang diprogramkan kabupaten Gunung Kidul sejak tiga tahun terakhir. Meski sudah dikenal banyak orang, pemerintah merasa capaian atas program ini belum sesuai harapan. Karena pada kenyataannya sebagian besar masyarakat Gunung Kidul tidak memahami konsep city branding yang dijalankan oleh pemerintah kabupaten mereka sendiri belum dirasa maksimal. Menggunakan pendekatan kualitatif dan kuantitatif, dengan metode wawancara mendalam dan penyebaran kuesioner, penelitian ini bertujuan untuk menganalisis pengaruh City branding Kabupaten Gunungkidul pada kunjungan wisatawan Kabupaten Gunungkidul. Teori citybranding dan teori persepsi akan mengungkap seberapa jauh pemahaman masyarakat asli gunung Gunung Kidul terkait elemen-elemen yang ada dalam city branding di kabupaten mereka sendiri.
\end{abstract}

Kata Kunci: city branding, minat berkunjung, wisatawan Gunungkidul.

Abstract: GUNUNGKIDUL HANDAYANI is a tagline of city branding programmed by Gunung Kidul district for the past three years. Although it is well known to many people, the government feels that the achievements of this program have not met expectations. Because in reality most of the Gunung Kidul people do not understand the concept of city branding run by their own district government has not been felt to be maximal. Using qualitative and quantitative approaches, with in-depth interviews and questionnaire dissemination methods, this study aims to analyze the influence of City branding in Gunungkidul Regency on tourist visits in Gunungkidul Regency. The citybranding theory and perception theory will reveal how far the Gunung Gunung Kidul indigenous people understand the elements in city branding in their own district.

Keywords: city branding, interest to visit, Gunungkidul tourists.

Zuefa Choirunnisa Mahasiswa Magister Seni Rupa Pascasarjana Universitas Sebelas Maret Surakarta, email: zuefachoirunnisa96@gmail.com.Dr. Deny Tri Ardianto M.A dan Dr. Rahmanu Widayat M.Sn Dosen Magister Seni Rupa Pascasarjana Universitas Sebelas Maret Surakarta 
Zuefa Choirunnisa, Deny Tri Ardianto dan Rahmanu Widayat, ANALISIS PENGARUH CITY BRANDING "GUNUNGKIDUL HANDAYANI"

\section{PENDAHULUAN}

City branding (identitas kota) berasal dari dua kata yaitu city dan branding. Awalnya diambil dari kata branding (identitas) yang dapat disusun menjadi sebuah kalimat menjadi city branding. Menurut Chaniago (2002) menyatakan bahwa City branding adalah tahapan suatu daerah untuk membentuk suatu identitas atau ciri khas suatu daerah agar lebih mudah dikenal oleh masyarakat umum juga kepada target market agar banyak investor yang melirik daerah tersebut. City branding pada dasarnya lebih menitikberatkan kepada pengelolaan, citra dan komunikasi yang digunakan dalam proses memperkenalkan daerah tersebut berdasarkan pernyataan Kavaratzis (2014:1) Berdasarkan beberapa pendapat di atas dapat disimpulkan bahwa identitas suatu daerah harus mudah diingat oleh orang yang sedang berkunjung ke daerah tersebut, karena dengan adanya city branding perekonomian daerah tersebut akan sangat berpengaruh.

Kabupaten Gunungkidul yang memiliki branding "GUNUNGKIDUL HANDAYANI" berupaya memberikan identitas kabupaten dengan tagline tersebut agar mudah diingat wisatawan. Kabupaten Gunungkidul merupakan satu dari 5 kabupaten di D.I.Yogyakarta yang memiliki banyak potensi dalam bidang pariwisata. Kabupaten Gunungkidul berpusat di Kota Wonosari. Luas daerah tersebut adalah 1.485,36 km2/ sekitar 46,63\% dari luas D.I.Yogyakarta. Kabupaten Gunungkidul dibagi menjadi 18 Kecamatan dan 144 desa yang tersebar di berbagai tempat yang memiliki potensi pariwisata berbeda beda.

Sebagai daerah kabupaten yang saat ini mulai berkembang menjadikan Kabupaten, Gunungkidul memilih bentuk walang (Belalang) pada City branding daerah tersebut karena selama ini belum menggunakan ikon di kabupaten tersebut, hanya tulisan GUNUNGKIDUL HANDAYANI saja, tanpa ada ikon Gunungkidul yang di sana banyak sekali ditemukan walang (belalang). Hampir sepanjang jalan banyak pedagang yang menjajakan walang (belalang) untuk dikonsumsi. Dengan alasan inilah, walang (belalang) dianggap bisa menjadi ikon 
Kabupaten Gunungkidul. Terlihat pada tahun 2018, Gunung kidul sudah menggunakan bentuk Walang (Belalang) yang bentuknnya memiliki makna dan sudah banyak diaplikasikan di media placement Kabupaten Gunungkidul. Oleh karena itu, pemerintah membuat rebranding Kabupaten Gunungkidul sebagai "GUNUNGKIDUL HANDAYANI" yang menitiktekankan pada kemajuan daerahnya sekaligus juga untuk menarik visitor wisatawan lokal maupun asing dan membuat mereka nyaman selama berada di Kabupaten Gunungkidul. Tujuan lainnya adalah agar lebih mudah mengingat ikon kabupaten, yang berupa walang (belalang).

\section{KAJIAN TEORI}

City branding merupakan upaya pembentukan citra dari suatu daerah dalam hal ini Kabupaten Gunungkidul sebagai destinasi wisata dalam bidang inovasi strategis,ekonomi, sosial, komersial, kultural, dan peraturan pemerintah yang berlaku di daerah tersebut (Anholt, 2007). City branding merupakan citra atau gambaran suatu daerah dalam hal ini Kabupaten Gunungkidul yang bisa mengembangkan potensi yang ada di daerah tersebut.

Adapun keinginan berkunjung merupakan sikap dasar manusia berdasarkan keinginan yang muncul tanpa adanya paksaan dari pihak lain. Biasanya keingingan berkunjung juga didorong unsur ingin membeli sesuatu. Dalam hal ini adalah keinginan untuk mengunjungi suatu daerah tempat wisata. Keinginan itu bisa berupa minat membeli jasa atau barang (Schiffman dan Kanuk 2007: 201). Sedangkan menurut (Kotler dan Keller, 2009) menyatakan minat membeli sesorang dibagi atas dua faktor yaitu sikap orang lain dan faktor situasi yang tidak dapat diantisipasi.

\section{METODE PENELITIAN}

Adapun fokus penelitian yaitu (1) Seberapa berhasilkah pengaruh city branding "GUNUNGKIDUL HANDAYANI" terhadap peningkatan kunjungan 
Zuefa Choirunnisa, Deny Tri Ardianto dan Rahmanu Widayat, ANALISIS PENGARUH CITY BRANDING "GUNUNGKIDUL HANDAYANI"

wisatawan di Kabupaten Gunungkidul. (2) Harapan dari city branding Kabupaten Gunungungkidul terhadap pengenalan daerah kepada wisatawan baik lokal maupun asing. Subjek Penelitian antara lain Kepala Bidang (Kabid) Humas Penelitian, Pengembangan dan Pengendalian Kabupaten Gunungkidul (BAPPEDA) Rismiyadi; Purnomo Sumardamto selaku Seksi Promosi dan Informasi Dinas Pariwisata Kabupaten Gunungkidul; serta 60 responden wisatawan.

Jenis penelitian yang digunakan adalah penelitian kualitatif. Metode riset kualitatifnya dengan pola deskriptif, menjadikan data lapangan bercerita dikuatkan dengan teori yang sesuai sehingga didapatkan sebuah kesimpulan dan saran.

Penelitian yang dilakukan berlokasi di BAPPEDA Kabupaten Gunungkidul yang terletak di Jl. Satria No.3, Wonosari, Kabupaten Gunungkidul, Daerah Istimewa Yogyakarta dan Dinas Pariwisata yang terletak di Jl KH. Agus Salim No 126, Kepek Wonosari Kabupaten Gunungkidul. Sedangkan pengambilan data penelitian mulai dilakukan pada bulan Maret 2018 hingga selesai bulan Desember 2018.

Tahap analisis dilakukan terhadap berbagai aspek berdasarkan data dan informasi yang dikumpulkan. Analisis yang dilakukan berupa analisis deskriptif yang digunakan untuk menganalisis aspek daya tarik pariwisata dan aktivitas wisatawan terhadap pengaruh city branding Kabupaten Gunungkidul. Teknik pengumpulan data dilakukan peneliti dengan cara observasi lapangan, penyebaran quesioner, dan wawancara dengan pihak yang dianggap memahami permasalahan dalam penelitian ini. Data di dapatkan dengan cara pengamatan langsung di lapangan (observasi), wawancara dengan beberapa narasumber yang terkait dengan topik dan data diperoleh melalui beberapa sumber yang terkait serta studi pustaka yang mendukung, baik berupa teks, foto, maupun gambar lainnya. Adapun pengumpulan data yang dilakukan sebagai berikut. Observasi 
dilakukan kepada 60 responden wisatawan secara acak di berbagai tempat wisata yang ada di Kabupaten Gunungkidul.

Adapun wawancara merupakan metode pengumpulan data informasi dengan memberikan beberapa pertanyaan kepada informan yang paham atau lebih mengetahui objek yang diteliti terkait city branding; dalam hal ini oleh Kepala Bidang (Kabid) Humas Penelitian, Pengembangan dan Pengendalian Kabupaten Gunungkidul (BAPPEDA) Rismiyadi dan Purnomo Sumardamto selaku Seksi Promosi dan Informasi Dinas Pariwisata Kabupaten Gunungkidul. Kajian Literatur dilakukan untuk mencari pustaka atau teori yang mendukung dalam memecahkan masalah yang ditemukan dalam objek penelitian dalam hal ini menggunakan teori Brand Communication dan minat berkunjung berdasarkan teori pariwisata.

\section{HASIL DAN DISKUSI}

Dalam beberapa tahun belakangan ini, city branding Kabupaten Gunungkidul sudah dirasa cukup baik. Dapat dilihat dari indeks rata ratanya yang masuk ke dalam kategori tinggi. Wisatawan yang berdatangan ke Gunungkidul sudah banyak yang mengetahui tagline GUNUNGKIDUL HANDAYANI. Hampir di semua dinas yang terkait di Gunungkidul sudah menggunakan logo dan tagline di setiap media promosi. Seperti pada mobil dinas secara keseluruhan, pada stasionary dinas, kalender, water mark pada web site Dinas Pariwisata, pusat informasi pariwisata, dan sebagainya. Namun untuk pemahaman terhadap city branding Kabupaten Gunungkidul belum detail, hanya sekedar mengetahui saja. Terlebih lagi, di Kantor Bupati tempat wisata terkait juga tidak ditemukan City branding Kabupaten tersebut.

Melihat hasil penyebaran kuesioner dari responden, city branding Kabupaten Gunungkidul belum begitu berpengaruh terhadap kunjungan wisatawan. Justru mereka berkunjung ke daerah tersebut banyak yang tidak mengetahui apa itu City Branding, apalagi city branding Kabupaten Gunungkidul. 
Zuefa Choirunnisa, Deny Tri Ardianto dan Rahmanu Widayat, ANALISIS PENGARUH CITY BRANDING "GUNUNGKIDUL HANDAYANI"

Dari hasil penyebaran kuesioner yang dilakukan, responden yang berpartisipasi sebanyak $80 \%$ adalah warga luar daerah Kabupaten Gunungkidul dan sisanya 20\% adalah warga asli Gunungkidul. Untuk jenis kelamin responden dari hasil penyebaran kuesioner didapatkan responden perempuan lebih banyak dibandingkan dengan laki-laki. Dari survei yang dilakukan didapatkan hasil responden yang berjenis kelamin $70 \%$ adalah wanita dan sisanya $30 \%$ adalah laki laki. Usia responden yang berkunjung ke Kabupaten Gunungkidul bervariatif mulai dari anak muda hingga orang tua.

Dari hasil penyebaran kuesioner didapatkan hasil usia yang berkunjung ke Kabupaten Gunungkidul berusia 12 tahun hingga 65 tahun. Usia $12-25$ sebanyak $80 \%$ dan usia diatas 30 tahun sebanyak $20 \%$ dengan tingkat pendidikan responden di Kabupaten Gunungkidul mayoritas memiliki tingkat pendidikan meliputi SD 10\%; SMP \& SMA 70\%; lalu diikuti sarjana sebanyak 20\%. Pekerjaan responden meliputi guru, wiraswasta, pelajar, mahasiswa, petani, dan TNI.

Jenis transportasi yang digunakan ke Gunungidul adalah kendaraan pribadi. Dari hasil kuesioner menyatakan $85 \%$ angkutan yang digunakan adalah motor dan mobil dan 15\% menggunakan transportasi umum. Dari hasil kuesioner sumber informasi berasal dari internet dan sosial media. Dari kuesioner yang dilakukan, sekitar $40 \%$ responden mendapatkan informasi dari internet dan $60 \%$ menyatakan mengetahui informasi dari narasumber.

Tingkat pengetahuan responden tentang Brand Gunungkidul banyak yang sudah mengetahui. Dari hasil kuesioner yang dilakukan $66 \%$ responden sudah mengetahui brand Gunungkidul, sisanya 33\% menyatakan belum mengetahui brand tersebut. Sumber informasi brand Gunungkidul banyak diketahui dari Internet. Dari hasil kuesioner, 33\% responden menyatakan mereka mengetahui informasi brand dari internet dan sisanya $66 \%$ responden mengetahui dari sumber lain seperti pamflet/ brosur dan sebagainya. Brand destinasi banyak berpengaruh terhadap kunjungan wisatawan ke Kabupaten Gunungkidul. Dari hasil kuesioner 
76\% responden menyatakan brand destinasi Gunungkidul tidak mempengaruhi persepsi, sedangkan sisanya $34 \%$ menyatakan berpengaruh.

Berdasarkan hasil penyebaran kuesioner, akses menuju Kabupaten Gunungkidul sudah cukup mudah dijangkau karena jalan menuju sana merupakan jalan satu satunya menuju Gunungkidul. Berdasarkan hasil kuesioner sebanyak 76\% responden menyatakan kemudahan aksestabilitas wisata di Gunungkidul baik, sisanya $24 \%$ menyatakan kurangnya kemudahan akses menuju lokasi wisata di Gunungkidul.

Berdasarkan kualitas akomodasi menuju Gunungkidul dirasa masih kurang baik karena masih terhalang bis yang hanya berhenti di terminal saja namun untuk ke lokasi tempat wisata masih jarang ada. Berdasarkan hasil kuesioner, $63 \%$ responden menyatakan sarana trasportasi umum masih belum cukup terpenuhi, sedangkan 37 \% menyatakan cukup memadai karena mereka menggunakan transportasi pribadi. Kualitas pelayanan di tempat wisata daerah Gunungkidul sudah dirasa cukup nyaman. Berdasarkan hasil kuesioner, $76 \%$ responden menyatakan puas dengan pelayanan di tempat wisata di Gunungkidul namun 24 $\%$ menyatakan kurang puas. Adapun kualitas pelayanan fasilitas umum di tempat wisata daerah Gunungkidul sudah dirasa cukup nyaman. Berdasarkan hasil kuesioner, $66 \%$ responden menyatakan fasilitas umum yang tersedia sudah baik, sisanya $34 \%$ menyatakan belum baik.

Hasil wawancara dengan Kepala Bidang (Kabid) Humas Penelitian, Pengembangan dan Pengendalian Kabupaten Gunungkidul (BAPPEDA) Bapak Rismiyadi S.P M.Si menyatakan bahwa : Kabupaten Gunungkidul telah menerapkan konsep citybranding sejak 26 Mei 2015. Berdasarkan PERATURAN BUPATI GUNUNGKIDUL NO 22 TAHUN 2015 dengan tagline Kabupaten Gunungkidul adalah "Handayani", Logotype adalah tulisan "Gunungkidul" dan Ambigram adalah tulisan "gk" pada Logo city branding. Dari peresmian hingga sekarang sudah berjalan selama 3 tahun. 
Zuefa Choirunnisa, Deny Tri Ardianto dan Rahmanu Widayat, ANALISIS PENGARUH CITY BRANDING "GUNUNGKIDUL HANDAYANI" TERHADAP PENINGKATAN KUNJUNGAN WISATAWAN DI KABUPATEN GUNUNGKIDUL. 16 - 30

Hingga saat ini city branding masih belum dirasa berhasil karena masih terus mengalami pengembangan kedepannya agar harapan seluruh masyarakat bisa memahami city branding Kabupaten Gunungkidul. Karena masih banyak masyarakat yang belum mengetahui apa city branding Kabupaten Gunungkidul. Oleh sebab itu belum banyak dampak yang dirasakan sebab pengetahun tentang citybranding juga masih dirasa kurang.

Kabupaten Gunungkidul menggunakan perbandingan daerah lain dalam menerapkan city branding yaitu Kabupaten Kulonprogo, Kota Bandung dan Kota Malang. Pengaplikasian logo city branding sudah diterapkan di media placement seperti mobil dinas, bangunan baru di Gunungkidul, stationary dinas, water mark pada web, pusat informasi pariwisata Gunungkidul, dan sebagainya.

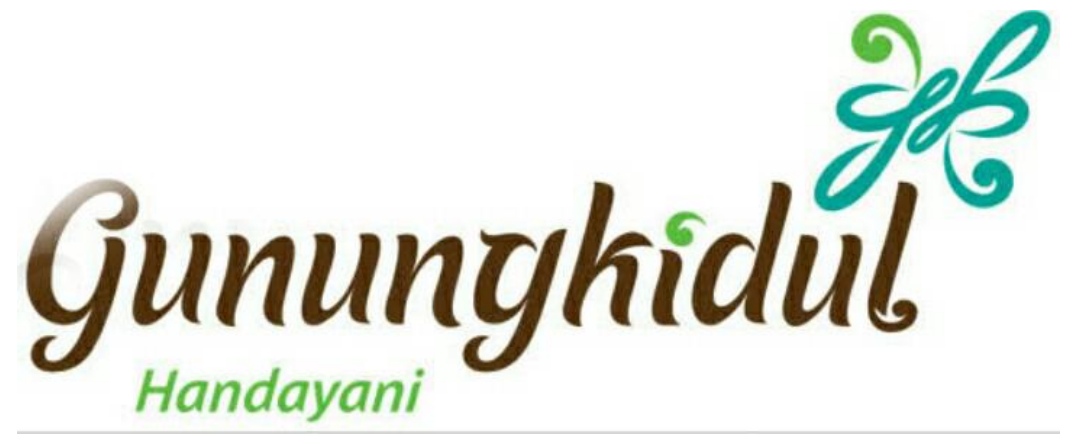

Gambar 1 Logo City Branding Kabupaten Gungkidul Sumber : BAPPEDA Kabupaten Gunungkidul 


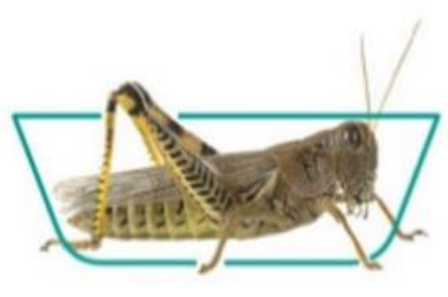

\section{Gununghidul}

\section{Gununghidul}

Gambar 2 Inspirasi Bentuk Walang (Belalang) di Logo Citybranding Sumber : BAPPEDA Kabupaten Gunungkidul

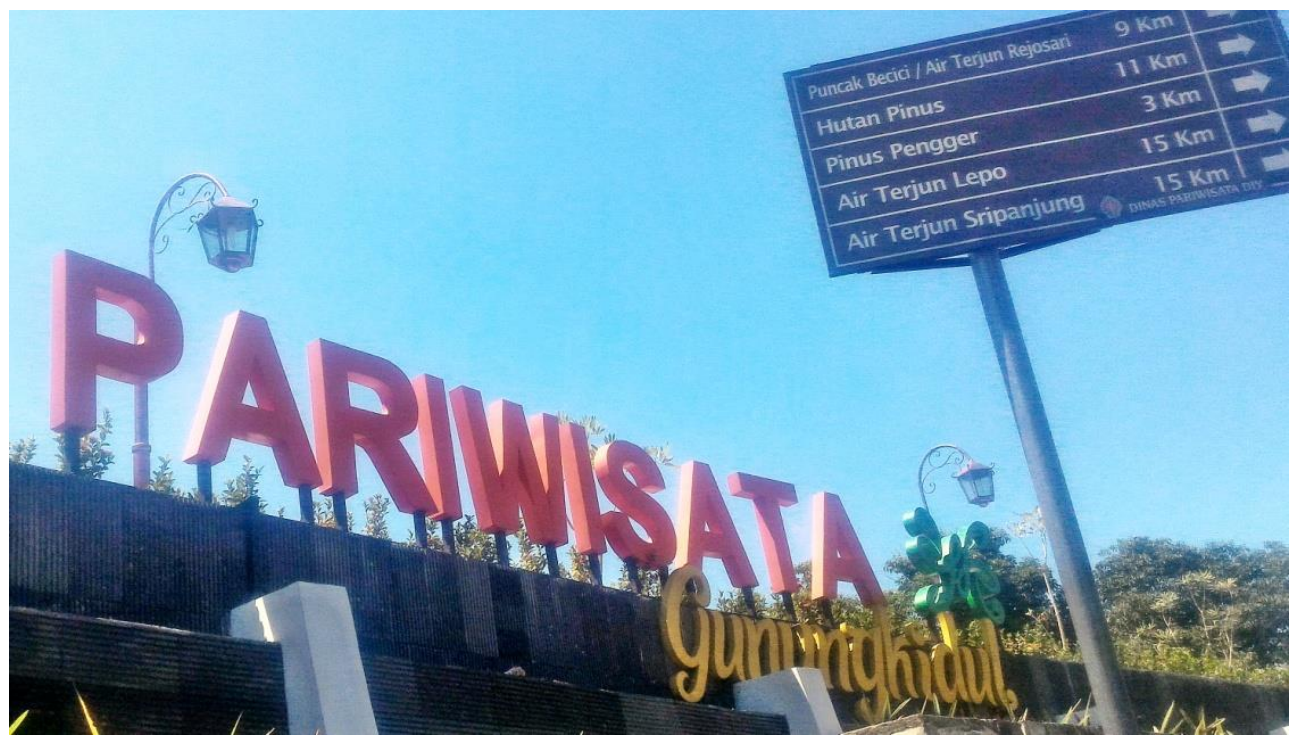

Gambar 3 Pengaplikasian logo city branding Pusat Informasi Pariwisata

Sumber : Choirunnisa, Ardianto, Widayat, 2019 
Zuefa Choirunnisa, Deny Tri Ardianto dan Rahmanu Widayat, ANALISIS PENGARUH CITY BRANDING "GUNUNGKIDUL HANDAYANI" TERHADAP PENINGKATAN KUNJUNGAN WISATAWAN DI KABUPATEN GUNUNGKIDUL. 16 - 30
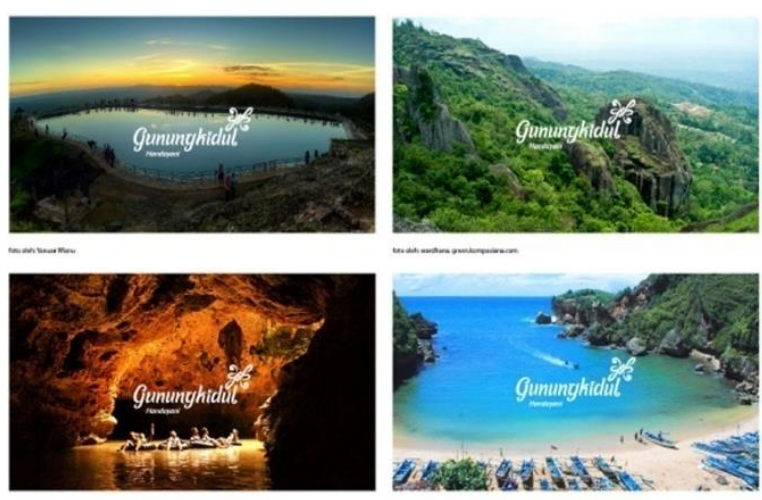

Gambar 4 Pengaplikasian logo city branding Watermark

Sumber : BAPPEDA Kabupaten Gunungkidul

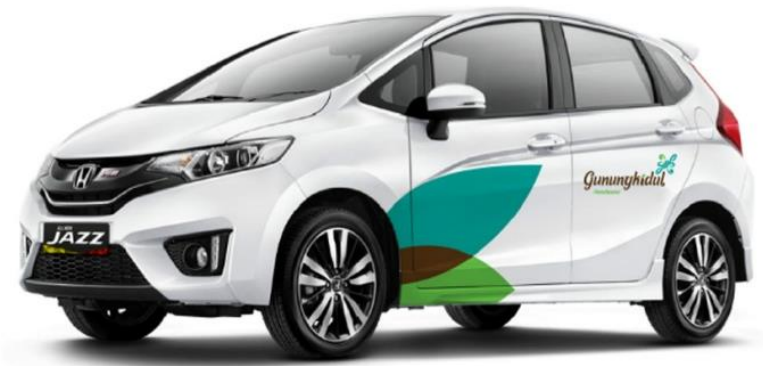

Gambar 5 Pengaplikasian logo city branding Mobil Dinas Sumber : BAPPEDA Kabupaten Gunungkidul

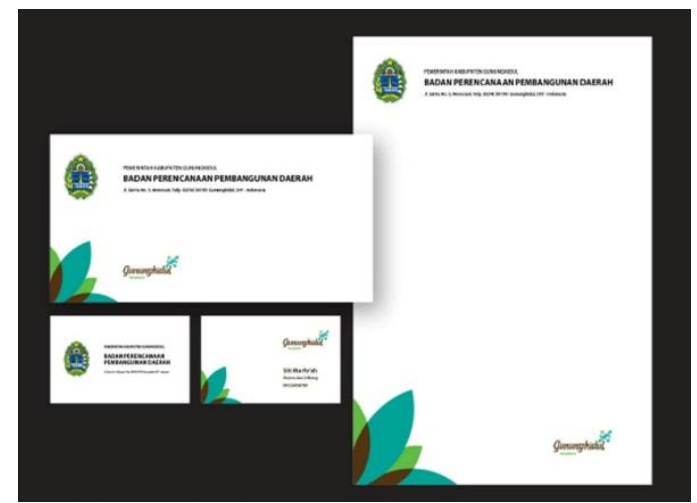

Gambar 6 Pengaplikasian logo city branding Stationary Sumber : BAPPEDA Kabupaten Gunungkidul 


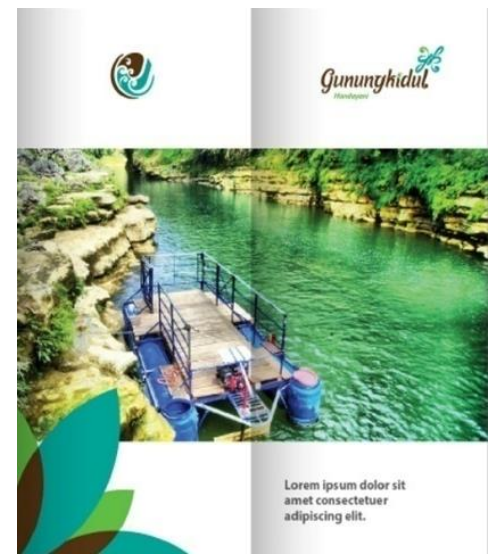

Gambar 7 Pengaplikasian logo city branding Flayer

Sumber : BAPPEDA Kabupaten Gunungkidul

Upaya yang dilakukan seluruh elemen yang terlibat satu sama lain dalam pengembangan citybranding Kabupaten Gunungkidul. Dengan adanya city branding dampak yang dirasakan adalah sangat mempengaruhi investasi devisa Kabupaten Gunungkidul. Sasaran utama city branding adalah masyarakat melalui instansi pemerintah Kabupaten Gunungkidul dan sektor pariwisata yang banyak merasakan dampak city branding.

Berikut merupakan hasil wawancara dengan Purnomo Sumardamto selaku Seksi Promosi dan Informasi Dinas Pariwisata Kabupaten Gunungkidul. Kabupaten Gunungkidul mempunyai beragam potensi perekonomian mulai dari pertanian, perikanan dan peternakan, hutan, flora dan fauna, industri, tambang serta potensi pariwisata. Kabupaten Gunungkidul juga mempunyai panjang pantai yang cukup luas terletak di sebelah selatan berbatasan dengan Samudera Hindia, membentang sepanjang sekitar $65 \mathrm{Km}$ dari Kecamatan Purwosari sampai Kecamatan Girisubo. Potensi hasil laut dan wisata sangat besar dan terbuka untuk dikembangkan.

Tingkat kepuasan wisatawan terhadap pariwisata di Kabupaten Gunungkidul tergolong baik, dapat dilihat dengan setiap tahunnya selalu mengalami peningkatan kunjungan dan setiap tahun selalu bermunculan destinasi wisata baru. Fasilitas yang disediakan di masing-masing lokasi wisata juga selalu 
Zuefa Choirunnisa, Deny Tri Ardianto dan Rahmanu Widayat, ANALISIS PENGARUH CITY BRANDING "GUNUNGKIDUL HANDAYANI"

mengalami pembaharuan guna memenuhi kebutuhan wisatawan selama berada di Kabupaten Gunungkidul.

Seperti yang telah diketahui bahwa Kabupaten Gunungkidul memiliki brand destinasi/ city branding "GUNUNGKIDUL HANDAYANI"; namun pada kenyataannya belum cukup berpengaruh terhadap sektor pariwisata. Selama ini wisatawan datang karena pengaruh promosi yang dilakukan bukan karena alasan city branding. Seharusnya konsep city branding yang sebenarnya adalah memperkenalkan ikon daerah tersebut sehingga dapat membantu pengembangan destinasi wisata yang ada di Kabupaten Gunungkidul. Tanpa adanya pengaruh city branding, tingkat kunjungan wisatawan di Gunungkidul selama 3 tahun terakhir ini selalu mengalami peningkatan setiap tahunnya baik wisatawan asing maupun domestik.

Tabel 1. Data Kunjungan Wisatwan Kabupaten Gunungkidul 2011 - 2016

\begin{tabular}{|c|c|c|c|}
\hline \multirow[t]{2}{*}{ Tahun } & \multicolumn{2}{|c|}{ Wisatawan } & \multirow[t]{2}{*}{ Jumlah } \\
\hline & Mancanegara & Domestik & \\
\hline 2011 & 1.299 & 615.397 & 616.698 \\
\hline 2012 & 1.800 & 998.587 & 1.000 .387 \\
\hline 2013 & 3.751 & 1.333 .687 & 1.337 .438 \\
\hline 2014 & 3.060 & 1.952 .757 & 1.955 .817 \\
\hline 2015 & 4.125 & 2.638 .634 & 2.642 .759 \\
\hline 2016 & 3.891 & 2.989 .006 & 2.992 .897 \\
\hline
\end{tabular}

( Sumber Dinas Pariwisata Kabupaten Gunungkidul)

Dari hasil pemaparan hasil kuesioner dan hasil wawancara diatas dapat dianalisis bahwa pengaruh city branding "GUNUNGKIDUL HANDAYANI" terhadap peningkatan kunjungan wisatawan di Kabupaten Gunungkidul dirasa masih belum berhasil. Adapun harapan dari city branding Kabupaten Gunungungkidul terhadap pengenalan daerah kepada wisatawan baik lokal adalah sebagai berikut :pertama, dapat memperkenalkan city branding Kabupaten Gunungkidul secara menyeluruh baik instansi yang terkait, masyarakat asli, maupun wisatawan luar daerah 
Kabupaten Gunungkidul. Kedua, dapat meningkatkan kunjungan wisatawan setiap tahunnya dari proses city branding yang dilakukan Kabupatan Gunungkidul. Selanjutnya, dapat dianggap sebagai daerah yang memiliki ciri khas oleh wisatawan yang berkunjung ke Kabupaten Gunungkidul. Terakhir, dapat digunakan untuk pencitraan yang kuat guna membuka investor untuk berinvestasi baik pada bidang wisata, tempat tinggal maupun penyelenggaraan events tertentu.

\section{KESIMPULAN}

Dari penelitian yang dilakukan dengan penyebaran kuesioner kepada 60 responden secara acak dan wawancara kepada BAPPEDA dan Dinas Pariwisata Kabupaten Gunungkidul diperoleh kesimpulan sebagai berikut: Pertama, kurangnya pengembangan terhadap city branding Kabupaten Gunungkidul kepada masyarakat baik lokal maupun pendatang ( luar daerah dan asing) karena saat ini belum banyak masyarakat yang mengetahui hal tersebut. Responden juga banyak yang tidak mengetahui apa itu city branding. Pengertian dari city branding saja mereka kurang memahami apalagi city branding Kabupaten Gunungkidul karena masih dirasa kurang informasi dari pemerintah kepada masyarakat. City branding Kabupaten Gunungkidul justru lebih banyak dipahami dan diketahui oleh masyarakat luar daerah yang berkunjung ke Kabupaten Gunungkidul dibandingkan warga asli daerah tersebut.

Dapat disimpulkan bahwa City branding Kabupaten Gunungkidul belum sepenuhnya mempengaruhi kunjungan wisatawan ke daerah tersebut karena dari hasil kuesioner yang dilakukan kunjungan wisatawan didapatkan hasil bahwa alasan wisatawan ke Gunungkidul adalah berkunjung ke tempat wisata tanpa mengetahui apa city branding Kabupaten Gunungkidul tersebut. Dengan kata lain, justru peningkatan wisatawan di Kabupaten Gunungkidul karena promosi yang 
Zuefa Choirunnisa, Deny Tri Ardianto dan Rahmanu Widayat, ANALISIS PENGARUH CITY BRANDING "GUNUNGKIDUL HANDAYANI"

gencar dilakukan Dinas Pariwisata untuk menarik wisatawan, bukan karena city branding Kabupaten Gunungkidul.

Dari penelitian yang telah dilakukan, dapat dikemukakan beberapa saran diantaranya pertama, melihat city branding Kabupaten Gunungkidul yang masih dirasa belum menggambarkan secara utuh tentang Kabupaten Gunungkidul secara keseluruhan membuat pemerintah perlunya melakukan pengkajian ulang atau rebranding logo city branding Kabupaten Gunungkidul. Pemahaman konsep city branding di Kabupaten Gunungkidul dirasa perlu untuk soalisasi kepada masyarakat. Selanjutnya, diperlukan pengenalan dan pemahaman City Branding Kabupaten Gunungkidul oleh masyarakat asli daerah Gunungkidul dahulu baru ke masyarakat luar agar pemahaman bisa sesuai dengan yang diharapkan pemerintah Kabupatan Gunungkidul.

Promosi pun perlu dilakukan guna meningkatan kunjungan wisatawan di Kabupaten Gunungkidul terkait city branding Kabupaten Gunungkidul. Contoh pengaplikasian logo baru diterapkan di beberapa bangunan dan mobil dinas Pemerintah Kabupaten Gunungkidul saja. Dikarenakan belum banyak ditemukan pengaplikasian logo city branding di Kabupaten Gunungkidul maka diharapkan lebih banyak media placement yang menggunakan city branding tersebut agar dapat memberikan informasi kepada masyarakat.

\section{PERNYATAAN PENGHARGAAN}

Penulis mengucapkan terimakasih atas seluruh partner pendukung dan para nara sumber serta instansi terkait yaitu BAPPEDA dan DINAS PARIWISATA Kabupaten Gunungkidul. Terimakasih juga kepada Kabid Humas Penelitian, Pengembangan dan Pengendalian Kabupaten Gunungkidul (BAPPEDA) Rismiyadi S.P M.Si serta Purnomo Sumardamto, S.Hut, MA, M.Eng selaku Seksi Promosi dan Informasi Dinas Pariwisata Kabupaten Gunungkidul. 


\section{DAFTAR PUSTAKA}

Anholt, Simon. 2007. Competitive Identity: The New Brand Management for Nations, Citiesand Regions. USA: Palgrave Macmillan.

Chaniago, Amran. Y.S. 2002. Kamus Lengkap Bahasa Indonesia. (Cet V). Bandung: Pustaka Setia.

Kavaratzis, Mihalis. 2004. From City Marketing to City Branding. Journal Towards a theoretical framework for developing city Brands. Place Branding, Vol. 1, No. 1.

Kotler,P. dan Keller, K.L. 2009. Manajement Pemasaran. Jilid I Edisi ke-13 Jakarta: Erlangga.

Schiffman \& Kanuk. 2007. Perilaku Konsumen. Edisi ke-7. Diterjemahkan oleh Zoelkifli Kasip. Jakarta: PT Indeks. 